vention and treatment of surgical pain. Patients with early renal failure NSAIDs are best avoided, or at least renal funciton should be carefully monitored.

William Code MD FRCPC

Department of Anaesthesia

Cowichan District Hospital

REFERENCES

1 Murray $M D$, Brater $D C$. Renal toxicity of the nonsteroidal anti-inflamatory drugs. Ann Rev Pharmacol Toxicol 1993; 33: 435-65.

2 Day RO, Henry DA, Muirden $K D$, et al. Non-steroidal anti-inflammatory drugs induced upper gastrointestinal haemorrhage and bleeding. Med J Aust 1992; 157: 810-2.

3 Moote CA. Complication associated with NSAIDs use for acute pain management. Perspectives in Pain Management 1993; 3: 3-6

4 Kehlet H, Dahl JB. Are perioperative nonsteriodal antiinflammatory drugs ulcerogenic in the short term? Drugs 1992; 5: 38-41.

5 Aitken HA, Burns JW, McArdle CS, Kenny GN. Effects of ketorolac trometamol on renal function. $\mathrm{Br} \mathrm{J}$ Anaesth 1992; 68: 481-5.

\section{Tracheal tube leak test}

To the Editor:

The paper on the leak test by Schwartz et al. was interesting. The conclusion that it is unreasonable to set an upper limit of leak pressure for changing all endotracheal tubes is contradicted by their results. Of the 242 patients studied $30(12 \%)$ were excluded because one or both examiners found that no leak occurred at $50 \mathrm{~cm}$ $\mathrm{H}_{2} \mathrm{O}$. Does this mean the authors would consider a leak at $50( \pm 18) \mathrm{cm} \mathrm{H}_{2} \mathrm{O}$ unacceptable?

Does the finding that the leak measured does not vary between observers invalidate the test? The need to determine fit of the endotracheal tube in the trachea and at the level of the cricoid ring derives from the fear that too tight a tube will cause pressure changes of the tissues at the level of the cricoid. These changes may cause transient problems such as stridor after extubation ${ }^{1}$ or may be directly related to later tracheal stenosis. ${ }^{2}$ The fact that a leak is detected at approximately $25( \pm 9.5) \mathrm{cm}$ $\mathrm{H}_{2} \mathrm{O}$ means that a pressure equal to the leak pressure is being exerted on the tracheal mucosa at the cricoid ring. This pressure should not exceed the perfusion pressure of the tissues at that level. In adults this has been estimated as $30 \mathrm{~cm} \mathrm{H}_{2} \mathrm{O}(22 \mathrm{mmHg}){ }^{3}$ If we no longer measure the leak pressure, there is no other way we can easily estimate how tight the tube is. The leak pressure may increase appreciably ${ }^{4}$ in children that undergo cardiac surgery, this may be due to subglottic oedema as a reflection of generalised oedema. The increase in the pressure may further compromise perfusion particularly if the arterial pressure is labile. A tube that fits well at the start of a case may become too tight. It is the duration and the age of the patient that seem to be the major determinants of tracheal stenosis. Thus the ex-premature neonate whose trachea has been intubated for some days is at particular risk. ${ }^{5} \mathrm{I}$ know of no study of leak pressure in this population.

\section{J.H. Smith MB MRCP FRCA \\ Newcastle-upon-Tyne \\ England}

\section{REFERENCES}

1 Koka BV, Jeon IS, Andre JM, MacKay I, Smith RM. Post intubation croup in children. Anesth Analg 1977; 56: 501-5.

2 Minnigerode B, Richter HG. Pathophysiology of subglottic tracheal stenosis in childhood. Prog Pediatr Surg 1987; 21: 1-7.

3 Seegobin $R D$, van Hasselt $G L$. Endotracheal cuff pressure and tracheal mucosal blood flow: endoscopic study of effects of four large volume cuffs. BMJ 1984; 288: 965-8.

4 Smith $J H$, O'Kelly $S W$. Brain swelling after coronary artery surgery (Letter). Lancet 1993; 342: 1370-1.

5 Weber TR, Connors RH, Tracy TF Jr. Acquired tracheal stenosis in infants and children. J Thorac Cardiovasc Surg 1991; 102: 29-34.

\section{REPLY}

We thank Dr. Smith for his response to the paper entitled "Tracheal Tube Leak Test - Is There Inter-observer Agreement?" We stated that we believe it is unreasonable to set a rigid upper limit of leak pressure for the changing of all endotracheal tubes. We also suggested that other factors such as duration of surgery, difficulty of intubation, risk of aspiration of gastric contents, surgical positoin, and history of croup or other airway abnormalities be considered when deciding if tight-fitting endotracheal tubes should be changed.' The optimal limits of leak pressure used to avoid laryngeal injury are unknown. Koka et al. suggested using $25 \mathrm{~cm} \mathrm{H}_{2} \mathrm{O}$, Litman and Keon use 40 $\mathrm{cm} \mathrm{H}_{2} \mathrm{O}^{3}$ In this study it was found there is considerable variation between two experienced observers in assessing leak pressure. Rather than set a rigid upper limit, the peak test should be used as one of multiple factors employed to determine if the endotracheal tube should be changed. We agree with Dr. Smith that the plan to undergo cardiopulmonary bypass should be added to the list of factors used when deciding to change tight-fitting endotracheal tubes.

Dr. Smith questions why we excluded patients in which one or both examiners found no leak at $50 \mathrm{~cm}$ of water. We were reluctant to raise the intrathoracic pressure to greater levels for fear of barotrauma. Since no specific leak pressure was assigned by one or both of the examiners in these patients, no interobserver difference could be calculated.

In summary, we did not intend to suggest that the leak pressure no longer be measured. We suggest that the absolute 